Rupantaran : A Multidisciplinary Journal

Vol. IV : pp 63-81, October, 2020

ISSN : 2091-0061

https://doi.org/10.3126/rupantaran.v4i1.34183

Research Management Cell (RMC)

Dhankuta Multiple Campus, Dhankuta

Tribhuvan University, Nepal

\title{
Nonlinear Impact of Perception of Organizational Politics on Satisfaction with Co-workers and Job Stress
}

\author{
Ganesh Bhattarai ${ }^{1}$ \\ Dhruba Raj Pokharel, PhD $^{2}$ \\ Prem Bahadur Budathoki ${ }^{3}$
}

\section{Abstract}

Large number of previous studies have tested that perception of organizational politics negatively impact on employee outcomes with linear relationship. To ascertain the condition where perception of organizational politics can be fruitful for employee outcomes, this study measured the nonlinear relationship of perception of organizational politics with satisfaction with co-workers and job stress. 453 employees working with microfinance companies in Kathmandu valley were surveyed to get cross sectional perceptual data. To infer the conclusion, data were analyzed adopting quantitative analysis, deductive reasoning approach as well as positivist research philosophy. Empirical evidences revealed the nonlinear impact of perception of organizational politics on satisfaction with co-workers and job stress. Both high and low levels of perceived organizational politics were harmful for satisfaction with co-workers and job stress. But a medium level of perception of organizational politics was fruitful for satisfaction with co-workers and job stress. The relationship between perception of organizational politics and satisfaction with co-workers was inverted $U$-shaped and the relationship between perception of organizational politics and job stress was U-shaped. Based on the findings, numbers of practical as well as theoretical implications are suggested.

Key Words: job stress, nonlinear relationship, perception of organizational politics, satisfaction with co-workers

1. Mr. Bhattrai is a Lecturer of Management at Nepal Commerce Campus, Kathamandu. Email: ganesh@ncc.edu.np

2. Mr. Pokhrel is Reader of Management at Nepal Commerce Campus, Kathmandu, Nepal.

3. Mr. Budathoki is Lecturer of Management at Mahendra Multiple Campus, Dharan. 


\section{Introduction}

Organizational politics has been ignored, but it is a real aspect of the work life in contemporary work setting (Buchanan, 2008). Perception of organizational politics is an individual's perception regarding others' self-interested acts or behaviors and these acts are frequently associated with the manipulation of organizational policies or often include coercive tactics, even at the expense of others, for targeted gains (Kacmar \& Ferris, 1991). Perception of organizational impacts on employees' attitudinal as well as behaviour outcomes like job satisfaction, turnover intention, job stress, satisfaction with supervisor, loyalty, innovation, management effectiveness, job anxiety, work intensity, work performance, organizational citizenship behavior, commitment burnout, work engagement, job involvement (Ferris 2002). However, natures of relationships were not stable across the samples or contexts (Fedor et al., 2008). Therefore, perception of organizational politics impacts either negatively or positively, or may be neutral to the employee outcomes (Chang et al., 2009).

Scholars Boswell et al. (2004), Buchanan and Badham (2008) Crawford et al. (2010), Ferris et al. (1989), LePine et al. (2005), Mayes and Allen (1977), Mintzberg (1983), and Rosen and Levy (2013) have tested the detrimental effects of perception of organizational politics on employee outcomes. Researchers like Ammeter et al. (2002), Kurchner-Hawkins and Miller (2006), Silvester (2008), and Valle and Perrewe (2002) have stated that employees' perception of organizational politics itself impacts neither positively nor negatively - it is neutral. These scholars further state the interactive effect of perception of organizational politics with the environment and individual is the major determinant to impact positively or negatively. Moreover, there are other researcher (e.g. Buchanan 2008; Butcher \& Clarke, 2003; Hochwarter et al. 2010) who have tested that perception of organizational politics positively impacts to employees as well as organization.

These inconsistent findings lead to think of the alternative ways to the established relationship between perception of organizational politics and its impacts on employees' attitudinal as well as behavioral outcomes. Definitely, as a field of scientific inquiry, the organizational sciences have assumed that the majority of phenomena are related linearly (Ferris et al., 2006). However, because there has been enough inconsistency in previous studies and probably insignificant findings are not submitted for publication (Rosenthal, 1979), therefore, it is proper to assume that there can be existed a nonlinear relationship as well in the relationship between perception of organizational politics to employee outcomes.

\section{Research Problems}

As stated in background section, such inconclusive findings created the dilemma to the managers that whether to promote or discourage or be indifference 
to the political environment those are exhibited in the workplace. Because there are theoretical and empirical evidences that perceived organizational politics effect sometimes detrimentally, sometimes positively and sometimes indifferently.

\section{Research Objectives}

In response to stated research gap and statement of problems, basically, this study aims to examine association of perception of organizational politics, satisfaction with coworker and job stress in the context of the microfinance companies working in Kathmandu Valley. Precise objectives were to examine the (a) nonlinear relationship of employees' perception of organizational politics with their satisfaction with coworkers, (b) nonlinear relationship of employees' perception of organizational politics with their job stress, and (b) situation where perceived organizational politic might be useful at workplace in terms of satisfaction with co-worker and job stress.

\section{Review of Literature}

Perception of organizational politics: Organizational politics is "a subjective state in which organizational members perceive themselves or others as intentionally seeking selfish ends in an organizational context when such ends are opposed to those of others" (Gandz \& Murray, 1980, p. 248). Gands and Murrary have suggested that politics should be conceived of as a subjective evaluation rather than abjective reality, because it is not actual politics (or political behavior) that matters most to organizational consequences, rather it is the subjective perception of workplace politics whether actual or not. Consistent with this argument, Lewin (1936) has argued that individuals respond on the basis of their perceptions of reality, not necessarily reality per se. Though corporate politics might appear as visible behaviours, employees' subjective feeling and understanding of these political tactics are more important and meaningful than the actual political tactics per se (Ferris \& Kacmar, 1992). Therefore, the most organizational psychologist has studied organizational politics as a perceptual and subjective phenomenon, consequently studies of perceived organizational politics dominated the study of actual political behaviours or tactics or strategies.

Job stress: Stress is the subjective judgment of one's resources relative to the demands one has to meet (Hobfoll, 1989). Job stress denotes the destructive mental, emotional and physical responses that emerge as discrepancies between the requirement of the job and employees capabilities or resources. When demands exceed resources, one is likely to experience work tension, anxiety etc. Employees' stress reflects in their health, motivation, productivity as well as satisfaction which ultimately lead to failure in career as well as burden to an organization. Kahn and Byosiere (1992) state stressful event might be something that causes anxiety, dissatisfaction, or poor health. Within the literature on organizational politics, Dipboye and Foster (2002) 
suggest that some individuals might conceptualize 'politics as stress and this way of approaching politics would treat politics/stress as a source of potentially harmful individual responses. Likewise, Vigoda (2002) stated that stress as an individual's response to work-related environmental stressors, one of which would be politics. Politics and stress are both phenomenological concepts and it is a sort of subjective appraisal of one's work environment or perhaps of one's response to one's work environment (Vigoda, 2006). Therefore, perceived organizational politics and job stress are closely related as individual level of construct. Job stress is a serious problem for the employees as well as an organization because it is related to the productivity, health as well as life satisfaction. Therefore, management should take proactive action to prevent job stress

Satisfaction with co-workers: Satisfaction with co-workers is the one of the facets of job satisfaction. Spector (1985) proposed the different facets of job satisfaction like pay satisfaction, promotion satisfaction, satisfaction with supervisor, benefit satisfaction, reward satisfaction, operating procedure satisfaction, satisfaction with co-workers, satisfaction with work itself, communication satisfaction etc. Satisfaction with co-workers refers the employees' perception of positivity in the relationship between and among co-workers at workplace. It is the employees' subjective evaluation of the working environment in terms of behaviour, cooperation, help, support, belief among the co-workers. If the relationship between co-workers is respectful, trustworthy, cooperative, transparent, selfishness, less, backbiting less, such environment contributes to satisfaction with co-workers. Employees' significant amount of times are spent with co-workers, if we don't count slept time, someone spends more time with co-workers rather than their family members, therefore organization should create such a working environment where employees are satisfied with each other.

\section{Nonlinear relationship of perception of organizational politics with} satisfaction with co-workers and job stress: Cropanzano et al. (1997) state perception of organizational politics as stressor at workplace and it is one of the many job demands. As perception of organizational politics increase anxiety will be increased in the same direction until at a point, then after an increase in perceived organizational politics does not continue to increase anxiety (Harris \& Kacmar, 2003) instead of decrease the level of anxiety. Aligned with Harris and Kacmar's logic, Hochwarter et al. (2010) argue that: (1) Politics at low levels may exhibit harmful effects (2) expansion of low to moderate levels may be beneficial, and (3) increases from moderate to excessive levels are detrimental or cause a leveling-off effect. Therefore, "it is essential to distinguish between separate segments of a job characteristic range; the nature of associations with employee reactions can differ between low, medium, and high levels of a job feature" (Warr, 1990, P. 293). From these perspectives we assumed that there might 
be other relationships between perception of organizational politics (as a stressor/job demand) and employee outcomes (e.g. satisfaction with co-workers, job stress) rather than well-established and usual linear relationship.

We purpose, here, Activation Theory (Scott, 1966) to discuss the possibility of the alternative relationship between perception of organizational politics and employee outcomes. Here, perceived politics is the stressor at workplace (Hochwarter, 2010) and employee outcomes can be both attitudinal and behaviour. Activation Theory explains that to generate arousal and social wrangling, workplace requires a certain level of job demands, therefore, to have proper arousal and wrangling perception of organizational politics is needed as external job demand. Activation Theory is particularly useful in describing when low levels of a job demand are detrimental to attitudes and behaviors (Janssen, 2001. Precisely, Activation Theory explains that a job demand at low levels is initially harmful because of its inability to generate arousal and lesser social wrangling in the work environment, because, employees' level of activation needed to engage in the workplace is largely deficient (Gardner, 1986). Therefore, employees accept a critical level of politics at workplace, and when such activity is lacking, few circumstantial indications exist to guide behaviour as a sufferer (Davis \& Lofquist, 1984)

Chung and Ross (1977, p. 119) state, "most skilled workers then will find their optimal levels of job satisfaction and productivity when their jobs are moderately enlarged and enriched". Similarly, certain amounts of a job demand are preferable at the workplace because this motivates employees' sensitivity to an active level (Selye, 1976). Warr (1994) reported that high job demands due to perceived organizational politics increase cognitive overload, subsequently prompting coping failures, hindering decision making, and facilitating a loss of control. Activation Theory further states that continually increases in the level of job demands from moderate to high levels will return detrimental outcomes (Champoux, 1992). Moreover, the Vitamin Model (Warr, 1987) acknowledges that excessive job demands promote attention switching, which leads to diminished concentration and achievement in both work and non-work contexts. Highly political workplaces reduce individuals' resources required to maintain or improve their status in the organization (Treadway et al., 2005). From the discussion of perception of organization politics as job demand and aligning it with Activation Theory, we came to set up that (1) low level of perceived organizational politics could not activate employees, (2) excessive level of perception of organizational politics cause to engage employees for making counter-strategy for others self-serving behaviour, and (3) a medium level of perception of organizational politics energies and activates employees' behaviour. Consequently, we postulate the following hypothesis. 
Hypothesis 1: There will be the nonlinear relationship between employees' perception of organizational politics and their satisfaction with co-workers exhibiting an inverted U-shaped relationship. It means higher and lower levels of perception of organizational politics will be associated with lower levels of satisfaction with co-workers, and a moderate level of perception of organizational politics will be associated with the highest level of satisfaction with co-workers.

Hypothesis 2: There will be the nonlinear relationship between employees' perception of organizational politics and their job stress exhibiting a U-shaped relationship. It means a higher and lower level of perception of organizational politics will be associated with the highest level of job stress, and a moderate level of perception of organizational politics will be associated with the low level of job satisfaction.

\section{Methods and Materials \\ Research Design}

To infer the causal relationship, perceptual cross-sectional data were analyzed adopting positivist research philosophy and quantitative research design. This design is normally considered as a more scientific approach to do social science research (Richard, 2009). Indeed, the ability to make correct predictions are one of the most outstanding characteristics of quantitative methodology and it may be valuable for evaluating theory and testing whether the theory holds up under a variety of circumstances and instances (Bhattarai, 2016).

\section{Measure}

All the measures used in this study except demographic variables were measured using five point Likert type scale. Five point scale was ranged from strongly disagree (1) to strongly agree (5). Respondents were requested to choose a best described scale (e.g. 5 for strongly agree) of them corresponding to each item. Already developed and tested measures were adopted in this study with rephrasing and contextualizing as needed.

Satisfaction with co-workers: Satisfaction with co-workers was measured using five item scale. Out of the five items, four items were adopted from the scale developed by Spector (1985). One new item was added to ensure the content validity in our contexts. Few sample items were: I enjoy with my co-workers, I get fair advice from co-workers when I ask something about in my difficult job situation. In this study, composite reliability was measured .94 .

Job stress: Job stress was measured using six item scale that was developed by House and Rizzo (1972). Few sample items were: Problems associated with my job have kept me awake at night, I often 'take my job home with me' in the sense 
that I think about it when doing other things. In this study, composite reliability was measured .93 .

Perception of organizational politics: This study used nine items scale to measure the perception of organizational politics. Three new items were added to the six-item measure scale of the Kacmar and Ferris (1991). Items were added to ensure the content validity of the construct in Nepalese context. These added items are: (1) In this organization, people do what is best for them, not what is best for the organization, (2) Here, people are more concentrated to please senior and powerful people who can help them, and (3) Here, individuals are assaulting each other in the back to look good in front of others. In this study, composite reliability was measured. 95.

\section{Population sampling and questionnaire administration}

Employees working with microfinance companies in Kathmandu valley are the population of the study and through nonrandom sampling method 650 employees were selected as the respondent. Out of the 550 distributed questionnaire, 499 (76\%) were filled up and returned back. Among them, only 480 (74\%) questionnaires were found ready to use for the study purpose. Moreover, Confirmatory Factor Analysis (CFA) considered only 453 (70 \%) responses to meet acceptable measurement model.

\section{Measurement model}

Confirmatory Factor Analysis (CFA) was carried out in AMOS version 23. First of all, all the 20 measuring items were loaded for the respective three latent constructs. Out of 20 measuring items, one item of the construct job stress was removed from the measurement model as they were loading less than .60 (Awang, 2015) in their respective latent construct. Then after, from the modification indices, five pairs of error terms within respective latent construct which showed the covariance error term more than .30 (Awang, 2015) were correlated to set as a free parameter estimate. Set as a free parameter were three pairs of error term from the construct perception of organizational politics and two pair of error term were from the construct job stress. Finally, a good model fit index was achieved $(\mathrm{CMIN} / \mathrm{DF}=2.79, \mathrm{CFI}=.97, \mathrm{NFI}=.96$, RMSEA $=.05$, and PCLOSE $=.12$ ).

\section{Validity}

Convergent validity: Convergent validity is achieved when all the items in a measurement model are statistically significant (Awang, 2015) and Average Variance Extraction (AVE) for every latent construct are greater than .50 (Awang, 2015; Hair et al., 2010). In this study AVE for each construct were more than .50 (i.e. perception of organizational politics $=.67$, satisfaction with supervisor $=.75$, and job stress $=.72$ ) 
and all the retained items in the measurement model were statistically significant. Therefore convergent validity was ensured.

Discriminant validity: Discriminant validity of the measures is ensured when correlation between predictor variables are less than .85 (Awang, 2015), or Maximum Shared Variance (MSV) is less than AVE (Hair et. al. 2010), or square root of AVE are higher than inter-construct correlation of corresponding factor (Gaskin \& Lim, 2016). In this study, MSV (i.e. perception of organizational politics was $=.08$, satisfaction with supervisor $=28$, and job stress $=.28$ ) was less than AVE in every case. The correlation between every latent construct was less than .85 (i.e. correlation between perception of organizational politics and satisfaction with co-workers $=-.14$, correlation between perception of organizational politics and job stress $=.28$, and correlation between satisfaction with supervisor and job stress $=$-. 53). Likewise, square root of every AVE was higher than their corresponding inter-construct correlation. Hence, discriminant validity was ensured.

\section{Common method variance}

In order to minimize the common method variance, we had followed the suggestions of the Podsakoff et al. (2003). For example, firstly, around 25\% (five items) questionnaire were reverse scored to reduce the potential effects of response pattern biases, by incorporating negatively worded items in the questionnaire, secondly, items measuring different variables (e.g. independent, moderating, and dependent) were offset in order, so that respondents could not recognize the corresponding constructs of the items. Beside these remedial measures, to know the degree of common method bias, the current study has tested the Harman's one-factor test, adopting the principal component factor analysis. It is one of the most widely used techniques that have been used by researchers to measure the problem of common method variance (Podsakoff et al., 2003). In the current study, the analysis revealed that three factor model were loaded on a single factor explained $32.11 \%$ of the variance. Cho and Lee (2012) stated that if the variance is less than $50 \%$, there will be no serious issue of common method bias in the analysis.

\section{Data analysis}

Data were analyzed in different stages employing International Business Machine (IBM) Corporation's Statistical Package for Social Sciences (SPSS) and Analysis of a Moment Structures (AMOS) version 23. Firstly, data were screened to refine further analysis. The respondent who missed to response more than $10 \%$ were removed and who missed less than $10 \%$ were replaced by the mean value of corresponding construct. Then after, unengaged data were removed from the direct observation as well as calculating the standard deviation. Data having a standard 
deviation less than .50 were removed as influential unengaged respondent (Gaskin, 2011). After addressing the issue of missing data and unengaged data, outlier data were removed. The entire respondent having P1 values of Mahalanobis d-square less than .05 were removed as an influential outlier (Gaskin, 2011). Then, remaining data were refined for further analysis. Secondly, goodness of fit index was calculated. To determine goodness of fit index of the collected data and calculated latent construct from observed variable, Confirmatory Factor Analysis (CFA) has been computed for all multiple scale items. Different series of CFA have been carried out as a trial and error method until result derived to the acceptable cutoff point of goodness of fit index (Awang, 2015). Goodness of fit index confirmed that collected and refined data were good fitted with a measurement model; therefore, factors were imputed from latent construct to observed variable (Gaskin, 2012) for further analysis. Fourthly, regression analysis was carried out using an ordinary least square method after satisfying it's all assumptions.

Hierarchical regression analyses were conducted to assess the linear and nonlinear relationship of perception of organizational politics with satisfaction with co-workers and job stress (Cohen et al., 2003). In the first step, demographic variables were entered as control variable in the model. The linear term of the perception of organizational politics was entered in the second step and followed by the nonlinear term of perception of organizational politics was entered in the model. For the confirmation of the nonlinear relationship, as a final step, cubed term of the perception of organizational politics was entered, because, a significant cubed term indicates as S-shaped relationship form (Hochwarter et al, 2010) between dependent and independent variables. The significance of the squared term indicates that the nonlinear term explains incremental criterion variance beyond that of the linear term (Stimson et al. 1981). After testing significance of nonlinear relationships, the graphs were plotted to show the form of the nonlinear relationship.

\section{Results and Discussion}

Demographic variable (e.g. gender, age, tenure, designation) were statistically insignificant to predict satisfaction with co-workers individually as well as jointly (as shown in the first step, Model 1, Table 1). Demographic variable explained the only $1 \%$ variance in the model. As shown in Step 2 of the Model 1 in Table 1, linear relationship of the perception of organizational politics to predict satisfaction with coworkers was inversely associated $\left(B=-16, \mathrm{p}<.01, \Delta \mathrm{R}^{2}=.03\right)$. Likewise, nonlinear relationship of perception of organizational politics was statistically significant $(B$ $\left.=-20, \mathrm{p}<.01, \Delta \mathrm{R}^{2}=.07\right)$ to predict satisfaction with co-workers with explaining additional $7 \%$ criterion variance (as shown in Step 3 of the Model 1 in Table 1). 
Therefore, Hypothesis 1 was supported. Step 4 of the Model 1 in Table 1 depicts the insignificant association $\left(B=.01, \mathrm{p}>.05, \Delta \mathrm{R}^{2}=.00\right)$ of cubic term of perception of organizational politics to predict satisfaction with co-workers which rejects the S-shape relationship. Rejection of an S-shape relationship further supports the best representation of inverted U-shaped relationship between perception of organizational politics and satisfaction with co-workers as proposed in Hypothesis 1.

Table 1: Regression Analysis: Nonlinear Association of Perception of Organizational Politics with Satisfaction with Co-workers and Job Stress

\section{Independent Variables}

\section{Dependent variables}

$\begin{aligned} & \text { Satisfaction with } \\ & \text { co-workers (Model 1) }\end{aligned}$
Job stress (Model 2)

\section{Step 1}

Gender

$-.11$

.17

Age

Tenure

$-.11$

$-.10$

Designation

.07

.02

Change in R2

$-.08$

.04

.01

$.02 *$

\section{Step 2}

Perception of organizational politics

Change in R2

$.03 * *$

$.13^{* *}$

\section{Step 3}

Perception of organizational politics2

Change in R2

\section{Step 4}

Perception of organizational politics3

$-.02$

.00
.01

.00

**, ${ }^{*}$, the mean difference is significant at the .01 , and .05 levels, respectively

Each demographic variable (e.g. gender, age, tenure, designation) were statistically insignificant to predict job stress, but it was significant in overall contributing $2 \%$ variance in the model (as shown in the first step, Model 2, Table 1). Likewise, as shown in Step 2 of the Model 2 in Table 1, linear relationship of the perception of organizational politics to predict job stress was positively associated 
$\left(B=.34, \mathrm{p}<.01, \Delta \mathrm{R}^{2}=.13\right)$. Likewise, nonlinear relationship of perception of organizational politics was statistically significant $\left(B=.19, \mathrm{p}<.01, \Delta \mathrm{R}^{2}=.06\right)$ to predict job stress with explaining additional $6 \%$ criterion variance (as shown in Step 3 of the Model 2 in Table 1). Hence, Hypothesis 2 was supported. Step 4 of the Model 2 in Table 1 depicts insignificant association $\left(B=01, \mathrm{p}>.05, \Delta \mathrm{R}^{2}=.00\right)$ of cubic term of perception of organizational politics to predict job stress which rejects the S-shape relationship. Rejection of S-shape further supports the best representation of U-shaped relationship between perception of organizational politics and job stress as projected in Hypothesis 2.

To show the form of the nonlinear relationship between predictor and criterion variables, we plotted the nonlinear relationship in the graph by first identifying points at high and low level of both predictor and criterion variable and then calculating points along the continuum (Aiken \& West, 1991). Figure 1 shows the nonlinear relationship between perception of organizational politics and satisfaction with co-workers, and figure 2 shows the nonlinear relationship between perception of organizational politics and job stress.

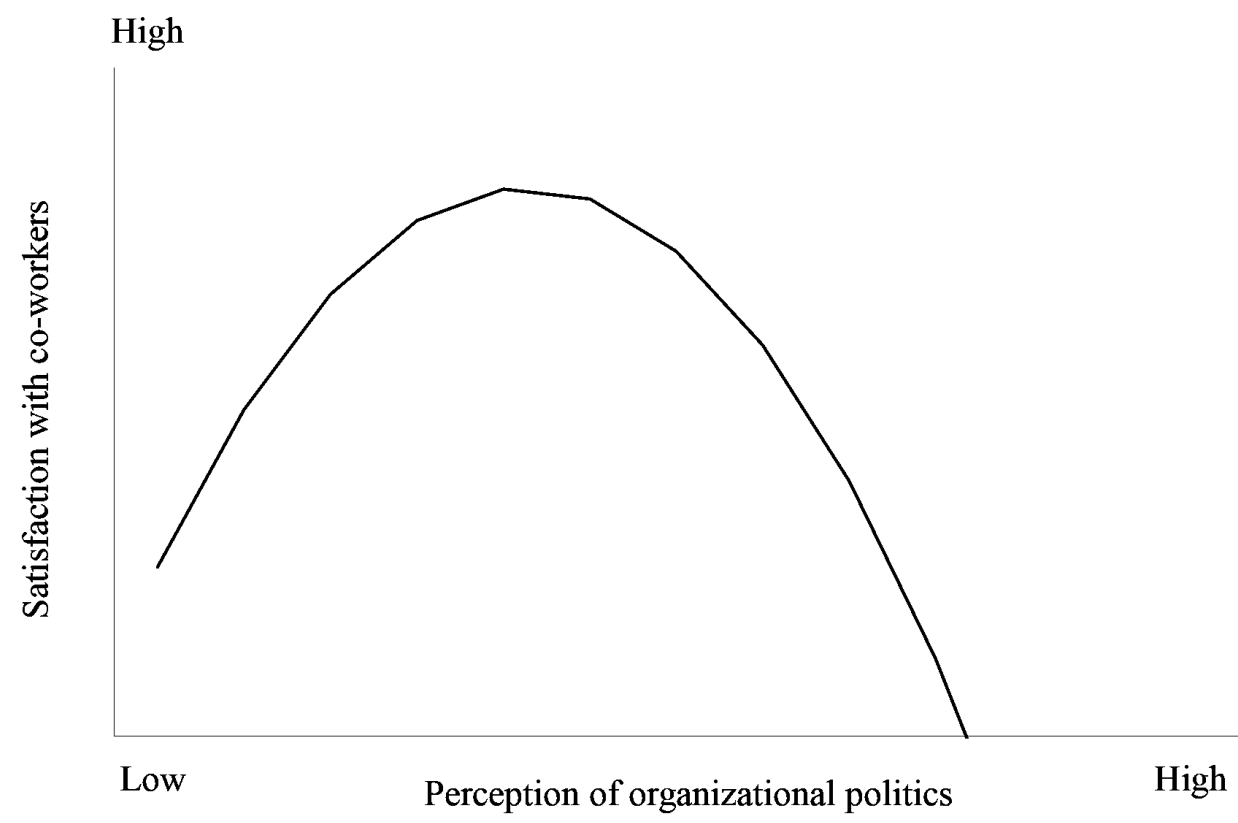

Figure 1: Nonlinear Relationship between Perception of Organizational Politics and Satisfaction with Co-workers.

As expected, Figure 1 shows the inverted U-shaped relationship between perception of organizational politics and satisfaction with co-workers. At both lowest level and the highest level of perception of organizational politics, employees' 
satisfaction with a co-worker was predicted at the lowest level, and when perception of organizational politics was at medium level there was the highest level of satisfaction with co-workers.

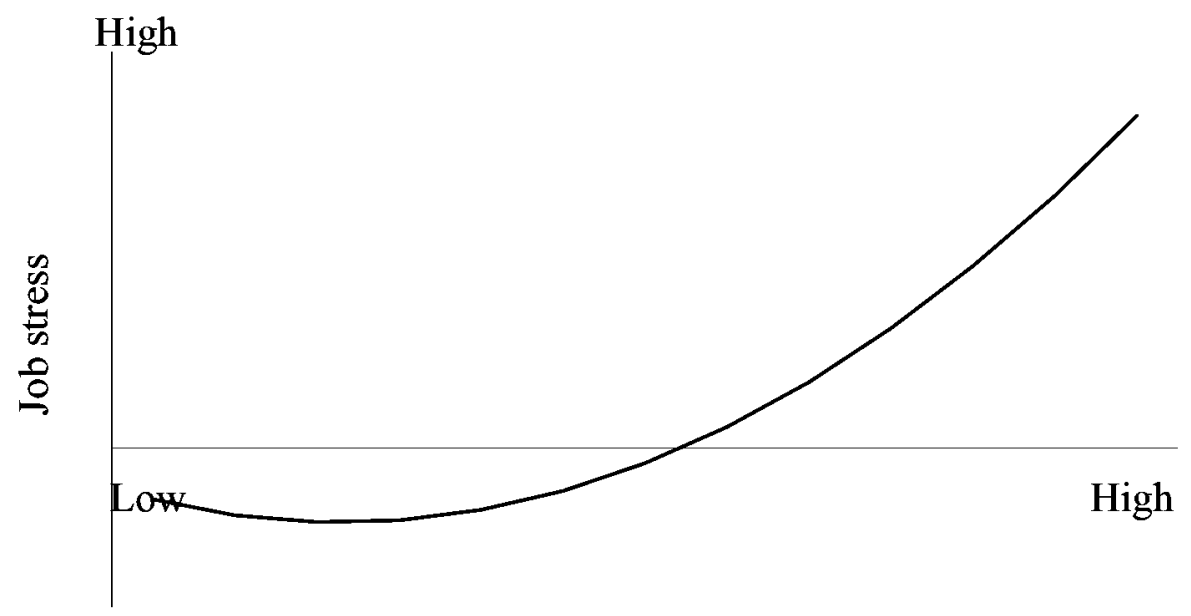

Perception of organizational politics

Figure 2: Nonlinear Relationship between Perception of Organizational Politics and Job Stress.

Figure 2 shows the nonlinear relationship between perception of organizational politics and job stress, but it is not much clear U-shaped relationship as expected. At the lowest and highest level of perception of organizational politics, there was not an equal level of job stress as the line of U-shape. However, at both points, relationship representing curve is pointing out to upside indicating job stress will be increased in both situations either consciously decreased or increased the perceived organizational politics. At medium level of perceived organizational politics, job stress was at the lowest level with slightly lenient to lower levels of perceived organizational politics.

This study tested the nonlinear relationship between perception of organizational politics and satisfaction with co-workers as inverted U-shaped relationship. This means both high and low levels of employees' perceived organizational politics is harmful to predict employee satisfaction with co-worker, but a medium level of perception of organizational politics is fruitful for satisfaction with co-workers. Likewise, this study tested the nonlinear relationship between perception of organizational politics and job stress as U-shaped relationship. This means a medium level of perception of organizational politics for job stress is beneficial and both high and low levels of perceived organizational politics are harmful for job stress.

These findings contradict with the large numbers of prior studies (e.g. Boswell et al., 2004; Crawford et al., 2010; Ferris et al., 1989; Ferris et al. 1996; Harrell- 
cook et al., 1999; LePine et al., 2005; Mayes \& Allen; 1977; Mintzberg, 1983; Parker et al., 1995; Rosen \& Levy; 2013; Valle \& Perrewe, 2000) which have tested the linear relationship of perception of organizational politics with different types of employee outcomes. However, our findings consist with the findings of Hochwarter et al. (2010) who have tested the nonlinear relationship of perception of organizational politics with employee job satisfaction and job tension in their both studies (Study 1 and Study 2). Moreover, these findings of the current study are aligned with the logic and empirical evidence of Activation Theory (Scott, 1966) as well as Vitamin Model of Warr (1987). Activation Theory state low level of job demand (here demand from perceived organizational politics at workplace) could not energies or activate employees at workplace, therefore it might be harmful to the employees as well as organization. In excessive level of politics, employees have to spend much time to question and make counter strategies for others' (supervisor, co-worker, subordinate etc. ) political tactics/strategies, and even they might feel unable to cope up with the highly political situation, therefor excessive level of workplace politics are also harmful for employees as well as organization. But a medium level of perceived organizational politics (as a job demand) energies and motivates employee to do work and make a good working environment that are benefited for both employees as well as organization. Likewise, Warr's (1987) Vitamin Model at workplace states that an optimum level of job demand is desirable at workplace, but either low or high levels of job demands are harmful alike the level of vitamin for human body.

Being contradicting findings regarding linear and nonlinear relationship between perception of organizational politics and employee outcomes, further study is necessary to do under different contexts with larger number of samples before generalizing the theory. The number of possible causes for such contradicting findings could be: unique feature of the human beings, workplace culture, employees' locus of control, attitudes towards power and politics game etc. Therefore, further studies are suggested to carry out controlling the effect of human nature (e.g. negativity, competitive spirit, and motivational factors), culture (e.g. national culture, organizational culture), employees' perceived power, perceived control in the decision making process etc. so that theory will be more refined.

\section{Conclusion}

This study concludes that relationships of perception of organizational politics with satisfaction with co-workers and job stress are nonlinear. The relationship between perception of organizational politics and satisfaction with co-workers is inverted U-shaped, and the relationship between perception of organizational politics and job stress is U-shaped. More precisely: (1) minimum level of employees' perceived 
organizational politics is harmful to predict employees' satisfaction with co-workers as well as job stress (2) medium level of perception of organizational politics is fruitful for satisfaction with co-workers as well as job stress, and (3) high level of perception of organizational politics are harmful for satisfaction with co-worker and job stress

\section{Implications of the Study}

Practical implications: As concluded in this study, a medium level of perception of organizational politics is needed for high level of satisfaction with co-workers as well as low level of job stress. Practically, managers can improve their employees' satisfaction with co-workers and minimize job stress maintaining an optimum level of organizational politics. They have to take proper intervention if there are either low levels or high levels of politics at workplace. For example, if there are no (or less) politics at the workplace, the manager may create competition among employees for limited sources or opportunities (e.g. competency based promotion), and if there are excessive levels of organizational politics, managers can make employees to participate in the decision making process to minimize the effect of the high level of perception of organizational politics (Witt et al., 2002).

Theoretical implications: Finding of this study as the nonlinear relationship of perception of organizational politics on satisfaction with co-worker and job stress is different than the large amount of prior studies (e.g. Bedi \& Schat, 2013; Chang et al., 2009; Miller et al., 2008) which were linear. Therefore, this finding adds an empirical evidence to think and study from the different perspective than as usual in the literature of organizational politics. Now, it's time to revisit and divert organizational politics study from nonlinear perspective. Moreover, perceived organizational politics impacts on number outcomes like job satisfaction, turnover intention, job stress, satisfaction with supervisor, loyalty, innovation, management effectiveness, job anxiety, work intensity, work performance, organizational citizenship behavior, commitment burnout, work engagement, job involvement (Ferris et al., 2002). Therefore, it is demanded to divert the avenue of the study to the nonlinear form of relationship between perception of organizational politics and these stated variables.

Limitation of the study: Though there is insufficient research about confounding influence in result due to Common Method Variance (Lai et al. 2013) from self-reported data, Podsakoff et al. (2003) have suggested number of procedural remedies to control findings not to deviate from the common method bias. Among the suggest remedies, obtaining data of the predictor and criterion variables from different sources as well as collecting data from in different time interval were not applied. Therefore, to measure the seriousness of common method variance we measured the Herman's single-factor test. Harman's single-factor test that implements principal component factor analysis 
of all the variables measuring items in a factor showed that a single factor explained $32.11 \%$ of the variance. Therefore, there is room to improve common method variance by measuring criterion and predictive construct from the different sources in different point of time (Podsakoff et al., 2003). Likewise, relationship between perceptions of organizational politics and its nonlinear relationship with satisfaction of with coworker and job stress might be influenced due environment as well as conditions of the individual (Silvester, 2008), but this study has not incorporated those intervening variables in the relationships between predictor and criterion variable.

\section{References}

Ammeter, A., Douglas, C., Gardner, W., Hochwater, W., \& Ferris, G. (2002). Toward a political theory of leadership. Leadership Quarterly, 13, 751-796.

Awang, Z. (2015). SEM made simple: A gentle approach to learning structural equation modeling. MPWS Rich Resources.

Bedi, A., Schat, A. C. H. (2013). Perceptions of organizational politics: A metaanalysis of its attitudinal, health, and behavioral consequences. Journal of Canadian Psychology, 54, 246-259. https://doi.org/10.1037/a0034549

Bhattarai, G. (2016). Perception of organizational politics and employee outcomes: Moderating role of core self-evaluation. Deutschland, Germany: LAP Lambert Academic Publishing. ISBN 978-3-330-02200-3.

Boswell, W., Olson-Buchanan, J., \& LePine, M. (2004). The relationship between work-related stress and work outcomes: The role of felt-challenge and psychological strain. Journal of Vocational Behavior, 64(1), 165-181.

Buchanan, D. (2008). You stab my back, I'll stab yours: Management experience and perceptions of organizational political behavior. British Journal of Management, 19, 49-64.

Buchanan, D., \& Badham, R. (2008). Power Politics and Organizational Change: Winning the Turf Game, SAGE.

Butcher, D., \& Clarke, M. (2003). Redefining managerial work: Smart politics. Management Decision, 41, 477-487.

Champoux, J. (1992). A multivariate analysis of curvilinear relationships among job scope, work context satisfaction, and affective outcomes. Human Relations, 45, 87-112.

Chang, C. H., Rosen, C. C., \& Levy, P. E. (2009). The relationship between perceptions of organizational politics and employee attitudes, strain, and behavior: A metaanalytic examination. Academy of Management Journal, 52, 779-801. 
Cho, J. C., \& Lee, J. W. (2012). Performance management and trust in Supervisors. Review of Public Personnel Administration, 32(3), 236-259. https://doi. org/10.1177/0734371X11421496

Chung, K., \& Ross, M. (1977). Differences in motivational properties between job enlargement and job enrichment. Academy of Management Review, 2, 113-122.

Cohen,J., Cohen,P., West, S., \&Aiken,L.(2003).Appliedmultipleregression/correlation analysis for the behavioral sciences. Erlbaum.

Crawford, E., LePine, J., \& Rich, B. (2010). Linking job demands and resources to employee engagement and burnout: A theoretical extension and meta-analytic test. Journal of Applied Psychology, 95(5), 834-848.

Cropanzano, R., Howes, J., Grandey, A., \& Toth, P. (1997). The relationship of organizational politics and support to work behaviors, attitudes, and stress. Journal of Organizational Behavior, 18, 159-180.

Dawis, R., \& Lofquist, L. (1984). A psychological theory of work adjustment. University of Minnesota Press.

Dipboye, R. L., \& Foster, J. B. (2002), Multi-level theorizing about perceptions of organizational politics, in Francis J. Yammarino, Fred Dansereau (eds), The Many Faces of Multi-level Issues: Research in Multi-Level Issues, (Vol. 1, pp.255 - 270). Emerald Group Publishing Limited. https://doi. org/10.1177/0149206319898506

Fedor,D., Maslyn,J.,Farmer,S., \&Bettenhausen,K.(2008). The contributions of positive politics to prediction of employee reactions. Journal Applied Social Psychology, $38,76-96$.

Ferris, G. R., \& Kacmar, K. M. (1992). Perceptions of organizational politics. Journal of Management, 18, 93-116.

Ferris, G. R., Frink, D. D., Galang, M. C., Zhou, J., Kacmar, K. M., \& Howard, J. L. (1996) Perceptions of organizational politics: Prediction, stress-related implications, and outcomes. Human Relations, 49, 233-266.

Ferris, G. R., Adams, G. , Kolodinsky, R. W., Hochwarter, W. A., Ammeter, A. P. (2002), Perceptions of organizational politics: Theory and research directions, in Francis Yammarino, Fred Dansereau (ed.) The many faces of multi-level issues: Research in Multi-Level Issues,(Vol. 1, pp.179254). Emerald Group Publishing Limited.

Ferris, G., Bowen, M., Treadway, D., Hochwarter, W., Hall, A., \& Perrewé, P. (2006). The assumed linearity of organizational phenomena: Implications for occupational stress and well-being. In P. Perrewé \& D. Ganster (Eds.), Research in occupational stress and well being: 205-235. 
Ferris, G., Russ, G., \& Fandt, P. (1989). Politics in organizations. In R. Giacalone \& P. Rosenfeld (Eds.), Impression management in the organization (pp. 143-170). Hillsdale, NJ: Lawrence Erlbaum.

Gandz, J., \& Murray, V. (1980). The experience of workplace politics. Academy of Management Journal, 23(2), 237-251.

Gardner, D. G. (1986). Activation theory and task design: An empirical test of several new predictions. Journal of Applied Psychology, 71(3), 411-418. https://doi. org/10.1037/0021-9010.71.3.411

Gaskin, J. \& Lim, J. (2016). Model fit measures: AMOS plugin. Gaskination's statwiki. Gaskin, J. (2011, March 25). Multivariate outliers. Retrieved from https://www. youtube.com/watch? $\mathrm{v}=0 \mathrm{vtgynhkH60}$

Gaskin, J. (2012, January 30). Imputing factor scores in AMOS. Retrieved from https://www.youtube.com/watch?v=dsOS9tQjxW8

Hair, J., Black, W., Babin, B., \& Anderson, R. (2010). Multivariate data analysis (7th ed.). Upper Saddle River. Prentice-Hall, Inc.

Harrell-Cook, G., Ferris, G. R., \& Dulebohn, J. H. (1999). Political behaviors as moderators of the perceptions of organizational politics-work outcomes relationships. Journal of Organizational Behavior, 20, 1093-1105.

Harris, K., \& Kacmar, K. (2003). New directions for research on politics perceptions: Suggestions and an illustrative example. In C. Schreisheim \& L. Neider (Eds.), New directions in human resource management: 91-110

Hobfoll, S. (1989). Conservation of resources: A new attempt at conceptualizing stress. American Psychologist, 44, 513-524.

Hochwarter, W., Ferris, G., Laird, M., Treadway, D., \& Gallagher, V. (2010). Nonlinear politics perceptions - work outcome relationships: A three study, five sample investigation. Journal of Management, 36(3), 740-763.

House, R. J., \& Rizzo, J. R. (1972). Toward the measurement of organizational practices: Scale development and validation. Journal of Applied Psychology, 56(5), 388-396. https://doi.org/10.1037/h0033444

Janssen, O. (2001). Fairness perceptions as a moderator in the curvilinear relationships between job demands, and job performance and job dissatisfaction. Academy of Management Journal, 44(5), 1039-1050. https://doi.org/10.2307/3069447

Kacmar, K. M., \& Ferris, G. R. (1991). Perceptions of organizational politics scale (POPS): Development and construct validation. Educational and Psychological Measurement, 51,193-205. 
Kahn, R. L., \& Byosiere, P. (1992). Stress in organizations. In M. D. Dunnette \& L. M. Hough (Eds.), Handbook of industrial and organizational psychology (p. 571-650). Consulting Psychologists Press.

Kurchner-Hawkins, R., \& Miller, R. (2006). Organizational politics: building positive political strategies in turbulent times. In Vigoda-Gadot, E., \& Drory, A. (eds), Handbook of Organizational Politics (pp. 328-352). Edward Elgar.

Lai, X., Li, F., \& Leung, K. (2013). A Monte Carlo study of the effects of common method variance on significance testing and parameter bias in hierarchical linear modeling. Organizational Research Methods, 16(2), 243-269. doi: $10.1177 / 1094428112469667$.

LePine, J., Podsakoff, N., \& LePine, M. (2005). A meta-analytic test of the challenge stressor-hindrance stressor framework: An explanation for inconsistent relationships among stressors and performance. Academy of Management Journal 48(5), 764-775.

Lewin, K. (1936). Principles of topological psychology. Mcgraw-Hill.

Mayes, B. T., \& Allen, R. W. (1977). Toward a definition of organizational politics. Academy of Management Review, 2, 672-677.

Miller, B. K., Byrne, Z. S., Rutherford, M. A., \& Hansen, A. M. (2009). Perceptions of organizational politics: A demonstration of the reliability generalization technique. Journal of Managerial Issues, 21, 280-300.

Mintzberg, H. (1983). Power in and around organizations. Englewood Cliffs. Prentice Hall.

Parker, C. P., Dipboye, R. L., \& Jackson, S. L. (1995). Perceptions of organizational politics: An investigation of antecedents and consequences. Journal of Management, 21(5), 891-912.

Podsakoff, P. M., MacKenzie, S. B., Lee, J. Y., \& Podsakoff, N. P. (2003). Common Method Biases in Behavioral Research: A Critical Review of the Literature and Recommended Remedies. Journal of Applied Psychology, 88(5), 879903. https://doi.org/10.1037/0021-9010.88.5.879

Richard, T. (2009). Qualitative versus quantitative methods: Understanding why qualitative methods are superior for criminology and criminal justice. Journal of Theoretical and Philosophical Criminology, 1 (1). Retrieved from: http://jtpcrim. org/January_Articles/Qualitative_Vs_Quantitave_Richard_Tewksbury.pdf.

Rosen, C. C., \& Levy, P. E. (2013). Stresses, swaps, and skill: An investigation of the psychological dynamics that relate work politics to employee performance. Human Performance, 26, 44-65. 
Rosenthal, R. 1979. The "file drawer problem" and tolerance for null results. Psychological Bulletin, 86: 638-641. Salancik, G., \& Pfeffer, J. (1978). A social information processing approach to job attitudes and job design. Administrative Science Quarterly, 23, 224-254.

Scott, W. E., Jr. (1966). Activation theory and task design. Organizational Behavior \& Human Performance, 1(1), 3-30. https://doi.org/10.1016/0030-5073(66) 90003-1

Selye, H. (1976). The stress of life. McGraw-Hill.

Silvester, J. (2008). The good, the bad, and the ugly: Politics and politicians at work. In G. P. Hodgkinson \& J. K. Ford (Eds.), International review of industrial and organizational psychology (Vol. 23, pp. 107-148). John Wiley \& Sons.

Spector, P. E. (1985). Measurement of human service staff satisfaction: Development of the Job Satisfaction Survey. American Journal of Community Psychology, 13(6), 693-713. https://doi.org/10.1007/BF00929796

Stimson, J., Carmines, E., \& Zeller, R. (1981). Interpreting polynomial regression. In P. Marsden (Ed.), Linear models in social research: 88-96.

Treadway, D., Adams, G., \& Goodman, J. (2005). The formation of political subclimates: Predictions from social identity, structuration, and symbolic interaction. Journal of Business and Psychology, 20: 201-219.

Valle, M., \& Perrewe, P. (2000). Do politics perceptions relate to political behaviors? Human Relations, 53(3), 359-386.

Vigoda, E. (2002). Stress-related aftermaths to workplace politics: The relationships among politics, job distress, and aggressive behavior in organizations. Journal of Organizational Behavior, 23, 1-21.

Warr, P. (1987). Work, unemployment and mental health. Oxford, Clarendon Press.

Warr, P. (1994). A conceptual framework for the study of work and mental health. Work and Stress, 8: 84-97.

Witt,L.A.,Andrews, M.C., \& Kacmar,K.M.(2000). Therole of participation in decisionmaking in the organizational politics-job satisfaction relationship. Human Relations, 53(3), 341-358. https://doi.org/10.1177/0018726700533003. 